\title{
ANALISIS CARA PENANGANAN DENGAN KEJADIAN INFEKSI SALURAN KEMIH PADA PASIEN DI POLIKLINIK UROLOGI RSUD DR M YUNUS BENGKULU
}

\author{
Liza Fitri Lina ${ }^{1}$, Ferasinta $^{2}$, Eva Oktavidiati ${ }^{3}$, Dwi Puji Lestari ${ }^{4}$ \\ 1, 2, 3, 4 Prodi Ilmu Keperawatan, Universitas Muhammadiyah Bengkulu \\ Email: $\underline{\text { lizafitrilina@umb.ac.id }}$
}

\begin{abstract}
ABSTRAK
Infeksi saluran kemih merupakan suatu keadaan patologis yang sudah sangat lama dikenal dan dapat di jumpai di berbagai pelayanan kesehatan primer sampai sub spesialistik. Tujuan penelitian ini adalah untuk menganalisis kejadian infeksi saluran kemih pada pasien di poliklinik urologi RSUD Dr. M Yunus Bengkulu. Desain penelitian yang digunakan adalah kualitatif dengan pendekatan deskriptif. Metode penelitian informan pada penelitian ini menggunakan teknik "Purposive Sampling". Sumber informasi pada penelitian ini adalah pasienyang berkunjung di poliklinik urologi RSUD Dr. M Yunus Bengkulu yang sudah menikah dan data dari rekam medic poliklinik urologi RSUD Dr. M Yunus Bengkulu sebanyak 5 pasien. Pengumpulan data menggunakan teknik wawancara mendalam. Hasil penelitian ini diperoleh tema yaitu aspek penanganan. Dalam aspek penanganan, pasien telah melakukan pemeriksaan dipoliklinik urologi RSUD Dr. M Yunus Bengkulu dan telah menjalankan pengobatan sehingga sudah merasa sehat. Kesimpulan yang diperoleh dalam penelitian ini adalah; Informan sedikit memahami tentang infeksi saluran kemih, seluruh informan baru pertama kali mengalami penyakit infeksi saluran kemih.
\end{abstract}

Kata Kunci : Infeksi Saluran Kemih, Penanganan 


\begin{abstract}
Urinary tract infection is a pathological condition that has been very long known and can be found in various primary health care to subspesialistik. The purpose of this study is to analyze the handling aspect with urinary tract infections in patients in urology clinic RSUD Dr.. M Yunus Bengkulu. The research design used was qualitative with descriptive approach. Informant research method in this research using technique "Purposive Sampling". The source of information in this study is the patients who visited the urology clinic RSUD Dr.. M Yunus Bengkulu who is married and data from medical record of urology clinic RSUD Dr. M Yunus Bengkulu as many as 5 patients. The data collection using in-depth interview technique. The results of this study obtained by 2 theme that is handling aspect. In the handling aspect, the patient has done the examination in urology clinic of RSUD Dr. M Yunus Bengkulu and has run the treatment so that it is feeling healthy. The conclusions obtained in this study are; Informants understand little about urinary tract infections, all new informants first experience urinary tract infections.
\end{abstract}

Keywords : handling, urinary track infection

\section{PENDAHULUAN}

Infeksi saluran kemih merupakan salah satu masalah kesehatan yang paling sering terjadi. American Urology Assocition (2016) menyatakan bahwa insiden infeksi saluran kemih diperkirakan 150 juta penduduk dunia pertahun. Infeksi saluran kemih di Amerika Serikat mencapai lebih dari 7 juta kunjungan setiap tahunnya. Kurang lebih $15 \%$ dari semua antibiotik yang diresepkan untuk masyarakat Amerika Serikat diberikan kepada penderita infeksi saluran kemih dan beberapa negara Eropa menunjukkan data yang sama. (Mosesa, dkk, 2017). Menurut Departemen Kesehatan Republik Indonesia tahun 2014, diperkirakan jumlah penderita penyakit infeksi saluran kemih di Indonesia mencapai 90-100 kasus per 100.000 penduduk per tahunnya atau sekitar 180.000 kasus baru per tahunnya (Darsono, dkk, 2016). Infeksi saluran kemih adalah infeksi yang disebabkan oleh mikroorganisme patogen yang naik dari uretra ke kandung kemih dan berkembang biak serta meningkat jumlahnya sehingga menyebabkan infeksi pada ureter dan ginjal. Menurut WHO, Infeksi saluran kemih (ISK) adalah penyakit infeksi kedua tersering pada tubuh sesudah infeksi saluran pernafasan dan sebanyak 8,3 juta kasus dilaporkan per tahun. Infeksi ini juga lebih sering dijumpai pada wanitadari pada laki-laki (Safitri, 2013). Ditambahkan oleh (Hooton, 2012), infeksi saluran kemih merupakan suatu keadaan patologis yang sudah sangat lama dikenal dan dapat dijumpai diberbagai pelayanan kesehatan primer sampai subspesialistik. Infeksi ini juga merupakan penyakit infeksi bakterial tersering yang didapat pada praktik umum dan bertanggung jawab terhadap morbiditas khususnya pada wanita dalam kelompok usia seksual aktif.

Berdasarkan data Rekam Medik di poliklinik urologi RSUD Dr. M. Yunus Bengkulu pada tahun 2016 tercatat 84 pasien infeksi saluran kemih, sedangkan pada tahun 2017 tercatat 106 pasien infeksi saluran kemih. Sedangkan, di beberapa 
rumah sakit lain jumlah pasien infeksi saluran kemih tercatat lebih sedikit, misalnya seperti di poliklinik penyakit dalam Rumah Sakit Bhayangkara TK III Bengkulu tercatat pada tahun 2016 sebanyak 71 pasien dan pada tahun 2017 sebanyak 97 pasien. Oleh karena itu dalam penelitian ini, penelitian akan dilakukan di poliklinik urologi RSUD Dr. M Yunus Bengkulu. Infeksi saluran kemih menjadi salah satu penyakit infeksi yang dapat membahayakan kesehatan manusia bahkan dapat berujung kepada kematian. Oleh karena itu, berdasarkan uraian di atas, penulis berkeinginan untuk melakukan penelitian yang berjudul "Analisis cara penanganan dengan kejadian infeksi saluran kemih pada pasien di poliklinik urologi RSUD Dr. M Yunus Kota Bengkulu".

\section{METODE PENELITIAN}

Jenis penelitian ini adalah penelitian kualitatif. Sumber informasi pada penelitian ini adalah pasien yang berkunjung di poli klinik urologi RSUD Dr. M Yunus Bengkulu yang sudah menikah dan data dari rekam medik poli klinik urologi RSUD Dr. M Yunus Bengkulu sebanyak 5 pasien.

\section{HASIL PENELITIAN DAN PEMBAHASAN}

\section{Hasil Penelitian}

Pada aspek penanganan, pasien telah melakukan pemeriksaan di poli klinik urologi RSUD Dr. M Yunus Bengkulu dan telah menjalankan pengobatan sehingga sudah merasa sehat.

\section{Pembahasan}

\section{Aspek Penanganan}

\section{a. Pemeriksaan}

Diagnosa infeksi saluran kemih diketahui setelah melakukan tes urine. Tes urine merupakan salah satu cara untuk mengetahui penyakit seseorang termasuk adanya infeksi saluran kemih. Suharyanto dan Madjid (2013) menyatakan bahwa pemeriksaan diagnostic infeksi saluran kemih adalah kultur urine, yaitu untuk menentukan criteria infeksi. Hitung koloni: sekitar 100.000 CFU permilimeter urine dari urine tampung aliran tengah. Adanya bakteri dalam specimen yang dikumpulkan melalui aspirasi jarum supra pubik kedalam kandung kemih. Dalam penelitian ini seluruh pasien menyatakan bahwa telah melakukan tes urine.

\section{b. Pengobatan}

Setelah terdiagnosa terinfeksi saluran kemih, informan sudah mendapatkan pengobatan dan kondisi saat ini sudah membaik. Ada beberapa metode pengobatan infeksi saluran kemih yang lazim dipakai, yaitu: pengobatan dosis tunggal (obat diberikan satu kali), pengobatan jangka pendek (1-2 minggu), pengobatan jangka panjang (3-4 minggu), dan pengobatan profilaktik (1 kali sehari dalam waktu 3- 6 bulan).

Obat tersebut merupakan obat untuk membebaskan saluran kemih dari bakteri dan mencegah atau mengendalikan infeksi berulang. Ada berbagai macam obat yang diberikan,salah satunya adalah antibiotik. Dalam pendekatan klinis pengobatan infeksi saluran kemih, pemilihan antibiotik adalah hal penting. Antibiotik yang sering digunakan adalah ampisilin, trimetoprimsulfametoksasol, kloramfenikol, sefotaksim, dan amikasim (Suharyanto 
dan Madjid,2013). Di dalam penelitian ini diperoleh informasi bahwa seluruh informan sudah menjalani pengobatan dan sudah merasa lebih baik. Hal ini mengindikasikan bahwa pasien patuh terhadap pengobatan dan obat yang diberikan juga merupakan obat yang tepat.

\section{KESIMPULAN}

Kesimpulan yang diperoleh dalam penelitian ini terdapat aspek penanganan, pasien telah melakukan pemeriksaan di poliklinik urologi RSUD Dr. M Yunus Bengkulu dan telah menjalankan pengobatan sehingga sudah merasa sehat.

\section{UCAPAN TERIMA KASIH}

Pada kesempatan ini, peneliti ingin mengucapkan terima kasih kepada berbagai pihak yang telah membantu terwujudnya penelitian ini :

1. Ketua Program Studi Ilmu Keperawatan, Universitas Muhammadiyah Bengkulu

2. Pihak RSUD Dr. M.Yunus Bengkulu

\section{DAFTAR PUSTAKA}

Darsono, V.P., Mahdiyah, D. dan Sari. M. 2016. Gambaran Karakteristik ibu hamil yang mengalami infeksi saluran kemih (ISK) di wilayah kerja Puskesmas Pekauman Banjarmasin. Jurnal Dinamika Kesehaan Vol. No.1 Juli 2016.

Hooton, T.M. 2012. Uncomplicated Urinary Tract Infection. The New
England Journal of medicine vol 366: 1028-37.

Lestari, T. 2014. Kumpulan teori untuk kajian pustaka penelitian kesehatan. Yogyakarta : Nuha medika.

Rowe, A.T dan Mehta, J.M. 2014. Diagnosis and Management of Urinary Tract Infection in Older Adults. [Online], vol.28(1):75-89. Dari: https://www.ncbi.nlm.nih.gov. $\quad[8$ Agustus 2017].

Safitri. N. 2013. Infeksi Saluran Kemih. Http://www.alodokter.com/infeksisaluran kemih/gejala. Diakses tanggal 03 Juni 2017.

Saleh, R.F, Othman R.S, Omar, K.A. 2016. The Relationship between urinary tract infection and low water intake and excessive consuming of fizzy drink. International Journal Of Medicine Research vol 1; issue 2 page 54-56.

Setiati. 2014. Ilmu Penyakit Dalam Buku Ajar Edisi VI Jilid II. Jakarta Barat : Interna Publishing.

Smeltzer, SC dan Bare, BG. 2008. Textbook of Medical-Surgical Nursing, 8th ed, Philadelphia: Lippincott Williams \& Wilkins.

Suharyanto, T dan Abdul Madjid. 2013. Asuhan Keperawatan Pada Klien dengan gangguan sistem perkemihan. Jakarta: Trans Info Media. 